\title{
Model research of phonon spectra of argyrodites family
}

\author{
I.I. Nebola ${ }^{1, *}$, A.Ya. Shteyfan ${ }^{1}$, V.I. Sidey ${ }^{1}$, A.F. Katanytsia ${ }^{1}$, I.P. Studenyak ${ }^{1}$, I.M. Shkyrta ${ }^{2}$ \\ ${ }^{1}$ Uzhhorod National University, \\ Voloshin Str., 54, 88000 Uzhhorod, Ukraine \\ ${ }^{2}$ Mukachevo State University, \\ Uzhhorodska Str., 26, 89600 Mukachevo, Ukraine
}

*E-mail: ivan.nebola@uzhnu.edu.ua

\begin{abstract}
Cu}_{6} \mathrm{PS}_{5} \mathrm{Br}$ compound belongs to the large family of complex chalcohalides crystallizing in the argyrodite structures. The main peculiarity of the copper-containing argyrodites is high ionic conductivity of $\mathrm{Cu}^{+}$ions, which makes it possible to use as the functional electronic materials. In the present study, the crystal structure of $\mathrm{Cu}_{6} \mathrm{PS}_{5} \mathrm{Br}$ argyrodite have been analyzed and described using the superspace symmetry concept. The program operating under the Maple environment and suitable for theoretically calculating the phonon spectra of the $\mathrm{Cu}_{6} \mathrm{PS}_{5} \mathrm{Br}$ argyrodite crystal has been developed. Zone structures have been calculated and presented for a series of model $\mathrm{Cu}_{6} \mathrm{PS}_{5} \mathrm{Br}$ phases. The eigenvalues of the generalized dynamic matrix have been found as well as the dispersion dependences have been built for the directions $\Gamma-\mathrm{X}-\mathrm{M}-\mathrm{R}-\Gamma-\mathrm{M}$ of the Brillouin zone.
\end{abstract}

Keywords: argyrodites, crystal structure, protocrystal, phonon spectrum, Maple environment.

doi: https://doi.org/10.15407/spqeo21.02.134

PACS 61.66.Fn

Manuscript received 12.04.18; revised version received 05.05.18; accepted for publication 27.06.18; published online 03.07.18.

\begin{abstract}
1. Introduction
In the recent years, investigations of superionic conductivity in solids have evolved into a broad interdisciplinary branch of science that encompasses physics, chemistry, materials science and instrumentation. Today, superionic conductors (SICs) are widely used in manufacturing rechargeable batteries, fuel cells, gas sensors, ion-selective electrodes, hightemperature heating elements, integrators and other devices [1-4]. One of the most prominent representatives of SICs is crystalline $\mathrm{Cu}_{6} \mathrm{PS}_{5} \mathrm{Br}$ compound that belongs to the structural family of argyrodites; and the main goal of this work was to investigate and model the phonon spectra inherent to the above mentioned compound.
\end{abstract}

\section{Material and methods}

The crystal structure of the high-temperature $\mathrm{Cu}_{6} \mathrm{PS}_{5} \mathrm{Br}$ phase was first reported in the papers [5 - 7], in which the lattice parameters, atomic coordinates, atomic displacement parameters (temperature factors) and site occupancy factors were given along with the interatomic distances and bond angles.

Analysis of the crystal structures typical for the argyrodite family has revealed high variability in the number of crystallographic positions and in the occupancy factors [8]. In our previous paper [9], for $a b$ initio calculations of the phonon frequencies in the $\Gamma$ point of the Brillouin zone of the $\mathrm{Cu}_{6} \mathrm{PS}_{5} \mathrm{Br}$ crystal, we have chosen the crystal structure model with the coordinates and occupancies presented in Table 1. In this paper, the same model was used for calculations of the dispersion dependences of the phonon spectrum in the Brillouin zone [8].

Such a crystal structure, according to [10], can be described as an occupancy-modulated face-centered cubic (FCC) superlattice with the base vectors $(4 a, 4 a$, $0),(4 a, 0,4 a)$, and $(0,4 a, 4 a)$. In order to implement the above description, we have used the $(3+3)$-dimensional space with the bases of the direct and reciprocal space in the metrics of the body-centered cubic (BCC) lattice with the base vectors $((-a, a, a),(a,-a, a),(a, a,-a))[11]$ : 
Table 1. Atomic positions and occupancies of the model $\mathrm{Cu}_{6} \mathrm{PS}_{5} \mathrm{Br}$ crystal structure.

\begin{tabular}{|c|c|c|c|c|c|c|}
\hline 蒙 & 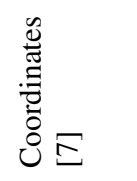 & 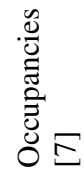 & 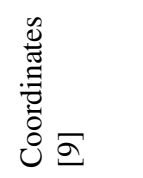 & 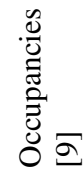 & 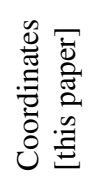 & 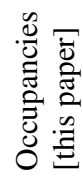 \\
\hline $\mathrm{Cu}(1)$ & $\begin{array}{l}0.02362, \\
0.25, \\
0.25)\end{array}$ & 0.624 & $\begin{array}{l}(0.01747, \\
0.25, \\
0.25)\end{array}$ & 1.0 & $\begin{array}{l}(0.0, \\
1 / 4, \\
1 / 4)\end{array}$ & 1.0 \\
\hline $\mathrm{Cu}(2)$ & $\begin{array}{l}0.01914, \\
0.30918, \\
0.30918)\end{array}$ & 0.376 & & 0.0 & & 0.0 \\
\hline $\mathrm{Br}$ & $(0,0,0)$ & 0.989 & $(0,0,0)$ & 1.0 & $\begin{array}{l}(0,0, \\
0)\end{array}$ & 1.0 \\
\hline $\mathrm{S}(1)$ & $\begin{array}{l}(0.25, \\
0.25 \\
0.25)\end{array}$ & 0.989 & $\begin{array}{l}(0.25 \\
0.25 \\
0.25)\end{array}$ & 1.0 & $\begin{array}{l}(1 / 4, \\
1 / 4, \\
1 / 4)\end{array}$ & 1.0 \\
\hline $\mathrm{S}(2)$ & $\begin{array}{l}0.62183, \\
0.62183, \\
0.62183)\end{array}$ & 1.0 & $\begin{array}{l}0.62183, \\
0.62183, \\
0.62183)\end{array}$ & 1.0 & $\begin{array}{l}5 / 8, \\
5 / 8, \\
5 / 8)\end{array}$ & 1.0 \\
\hline $\mathrm{P}$ & $\begin{array}{l}(0.5,0.5, \\
0.5)\end{array}$ & 1.0 & $\begin{array}{l}(0.5,0.5 \\
0.5)\end{array}$ & 1.0 & $\begin{array}{l}(1 / 2, \\
1 / 2, \\
1 / 2)\end{array}$ & 1.0 \\
\hline
\end{tabular}

$a_{1}=(-a, a, a, b / 4,-b / 4,-b / 4)$;

$a_{2}=(a,-a, a,-b / 4, b / 4,-b / 4)$;

$a_{3}=(a, a,-a,-b / 4,-b / 4, b / 4)$;

$a_{4}=(0,0,0,0, b, b)$;

$a_{5}=(0,0,0, b, 0, b)$;

$a_{6}=(0,0,0, b, b, 0)$;

$a_{1}^{*}=(0, \pi / a, \pi / a, 0,0,0)$;

$a_{2}^{*}=(\pi / a, 0, \pi / a, 0,0,0)$;

$a_{3}^{*}=(\pi / a, \pi / a, 0,0,0,0)$;

$a_{4}^{*}=(-\pi / 4 a, \pi / 4 a, \pi / 4 a,-\pi / b, \pi / b, \pi / b)$

$a_{5}^{*}=(\pi / 4 a,-\pi / 4 a, \pi / 4 a, \pi / b,-\pi / b, \pi / b)$;

$a_{6}^{*}=(\pi / 4 a, \pi / 4 a,-\pi / 4 a, \pi / b, \pi / b,-\pi / b)$.

\section{Results and discussion}

Using the bases (1), the relevant sets of (i) the superlattice positions and (ii) the modulation vectors $\mathbf{q} i$ were generated (Table 2). A complete set of 32 possible positions of atoms covers 10 orbits, while the set of 32 modulation vectors is separated into 10 stars. It allows to write a system of equations for determining the amplitudes of the mass modulation function $\rho i\left(\mathbf{q} i, \mathbf{b}^{*}\right)$. For the three-dimensional projection of the structure:

$$
M(n, 0)=\sum_{l=1}^{10} \rho_{l}\left(\mathbf{q}_{l}, 0\right) \sum_{m=1}^{\text {by star }} e^{i\left(\mathbf{q}_{l_{m}} n\right)}
$$

Table 2. Arrays of positions gathered in orbits and of modulation vectors gathered in stars.

\begin{tabular}{|c|c|c|c|c|}
\hline 言 & 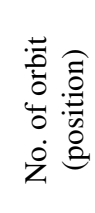 & 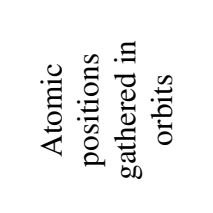 & 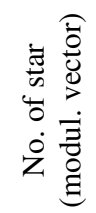 & 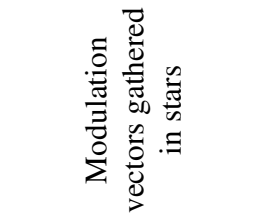 \\
\hline $\mathrm{Br}$ & $1(1)$ & {$[0,0,0]$} & $1(1)$ & {$[0,0,0]$} \\
\hline $\mathrm{P}$ & $2(2)$ & {$[4 a, 0,0]$} & $2(2)$ & {$[\pi / a, 0,0]$} \\
\hline \multirow[t]{3}{*}{$S(1)$} & $3(3)$ & {$[2 a, 2 a, 2 a]$} & $3(3)$ & {$[\pi / 2 a, \pi / 2 a, \pi / 2 a]$} \\
\hline & $4(4)$ & {$[-2 a,-2 a,-2 a]$} & $4(4)$ & $\begin{array}{r}{[-\pi / 2 a,-\pi / 2 a,} \\
-\pi / 2 a]\end{array}$ \\
\hline & $\begin{array}{l}5(5- \\
10)\end{array}$ & $\begin{array}{l}{[2 a, 0,0]} \\
{[0,2 a, 0]} \\
{[0,0,2 a]} \\
{[-2 a, 0,0]} \\
{[0,-2 a, 0]} \\
{[0,0,-2 a]}\end{array}$ & $\begin{array}{l}5(5- \\
10)\end{array}$ & $\begin{array}{l}{[\pi / 2 a, 0,0]} \\
{[0, \pi / 2 a, 0]} \\
{[0,0, \pi / 2 a]} \\
{[-\pi / 2 a, 0,0]} \\
{[0,-\pi / 2 a, 0]} \\
{[0,0,-\pi / 2 a]} \\
\end{array}$ \\
\hline \multirow[t]{4}{*}{$\mathrm{Cu}(1)$} & $\begin{array}{l}6(11- \\
16)\end{array}$ & $\begin{array}{l}{[2 a, 2 a, 0] ;} \\
{[0,2 a, 2 a]} \\
{[2 a, 0,2 a] ;} \\
{[-2 a, 2 a, 0] ;} \\
{[0,2 a,-2 a]} \\
{[-2 a, 0,2 a]}\end{array}$ & $\begin{array}{l}6(11- \\
16)\end{array}$ & $\begin{array}{l}{[\pi / 2 a, \pi / 2 a, 0] ;} \\
{[0, \pi / 2 a, \pi / 2 a] ;} \\
{[\pi / 2 a, 0, \pi / 2 a] ;} \\
{[-\pi / 2 a, \pi / 2 a, 0] ;} \\
{[0, \pi / 2 a,-\pi / 2 a] ;} \\
{[-\pi / 2 a, 0, \pi / 2 a]}\end{array}$ \\
\hline & $\begin{array}{l}7(17- \\
20)\end{array}$ & $\begin{array}{l}{[a, a, a] ;} \\
{[-a,-a, a] ;} \\
{[-a, a,-a]} \\
{[a,-a,-a]}\end{array}$ & $\begin{array}{l}7(17- \\
20)\end{array}$ & $\begin{array}{c}{[\pi / 4 a, \pi / 4 a, \pi / 4 a]} \\
{[-\pi / 4 a,-\pi / 4 a,} \\
\pi / 4 a] ; \\
{[-\pi / 4 a, \pi / 4 a,} \\
-\pi / 4 a] ; \\
{[\pi / 4 a,-\pi / 4 a,} \\
-\pi / 4 a]\end{array}$ \\
\hline & $\begin{array}{l}8(21- \\
24)\end{array}$ & $\begin{array}{l}{[-a,-a,-a] ;} \\
{[-a, a, a] ;} \\
{[a, a,-a] ;} \\
{[a,-a, a]}\end{array}$ & $\begin{array}{l}8(21- \\
24)\end{array}$ & $\begin{array}{r}{[-\pi / 4 a,-\pi / 4 a,} \\
-\pi / 4 a] ; \\
{[-\pi / 4 a, \pi / 4 a, \pi / 4 a] ;} \\
{[\pi / 4 a, \pi / 4 a,-\pi / 4 a] ;} \\
{[\pi / 4 a,-\pi / 4 a, \pi / 4 a]}\end{array}$ \\
\hline & $\begin{array}{l}9(25- \\
28)\end{array}$ & $\begin{array}{l}{[3 a, 3 a, 3 a]} \\
{[-3 a,-3 a, 3 a]} \\
{[-3 a, 3 a,-3 a]} \\
{[3 a,-3 a,-3 a]}\end{array}$ & $\begin{array}{l}9(25- \\
28)\end{array}$ & $\begin{array}{c}{[3 \pi / 4 a, 3 \pi / 4 a,} \\
3 \pi / 4 a] ; \\
{[-3 \pi / 4 a,-3 \pi / 4 a,} \\
3 \pi / 4 a] ; \\
{[-3 \pi / 4 a, 3 \pi / 4 a,} \\
-3 \pi / 4 a] ; \\
{[3 \pi / 4 a,-3 \pi / 4 a,} \\
-3 \pi / 4 a]\end{array}$ \\
\hline$S(2)$ & $\begin{array}{l}10(29 \\
-32)\end{array}$ & $\begin{array}{r}{[-3 a,-3 a,} \\
-3 a] ; \\
{[-3 a, 3 a, 3 a] ;} \\
{[3 a, 3 a,-3 a] ;} \\
{[3 a,-3 a, 3 a]}\end{array}$ & $\begin{array}{l}10(29 \\
-32)\end{array}$ & $\begin{array}{c}{[-3 \pi / 4 a,-3 \pi / 4 a,} \\
-3 \pi / 4 a] ; \\
{[-3 \pi / 4 a, 3 \pi / 4 a,} \\
3 \pi / 4 a] ; \\
{[3 \pi / 4 a, 3 \pi / 4 a,} \\
-3 \pi / 4 a] ; \\
{[3 \pi / 4 a,-3 \pi / 4 a,} \\
3 \pi / 4 a]\end{array}$ \\
\hline
\end{tabular}

where $M(n, 0)$ is the mass of atom in the $n$ position $(\Delta n=0), l$ defines the number of the star, and $m$ is the number of the vector of the star. 


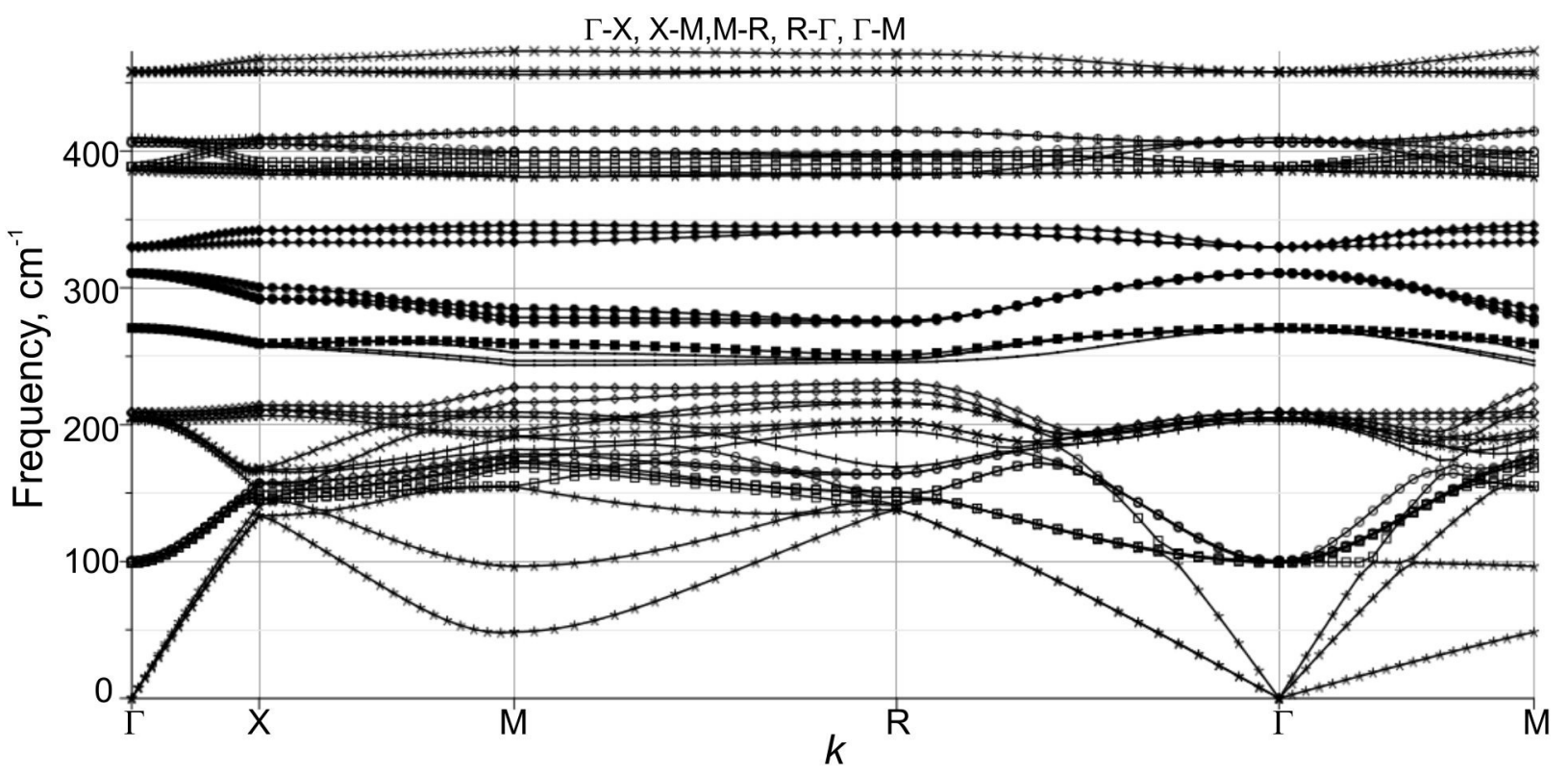

Fig. 1. Phonon spectra of the $\mathrm{Cu}_{6} \mathrm{PS}_{5} \mathrm{Br}$ crystal calculated for the selected power constants $\alpha_{1}=114 \mathrm{~N} / \mathrm{m}, \alpha_{2}=2.4 \mathrm{~N} / \mathrm{m}, \alpha_{3}=0.8 \mathrm{~N} / \mathrm{m}$, $\alpha_{4}=0.6 \mathrm{~N} / \mathrm{m}, \alpha_{5}=0.5 \mathrm{~N} / \mathrm{m}, \alpha_{6}=0.6 \mathrm{~N} / \mathrm{m}$ in Eq. (6).

By solving the above system of equations, one can obtains $\rho i\left(\mathbf{q} i, \mathbf{b}^{*}\right)$ :

$$
\begin{aligned}
& 32 \rho_{1}=M_{1}+M_{2}+M_{3}+M_{4}+6 M_{5}+6 M_{6}+ \\
& +4 M_{7}+4 M_{8}+4 M_{9}+4 M_{10} \text {, } \\
& 32 \rho_{2}=M_{1}+M_{2}+M_{3}+M_{4}+6 M_{5}+6 M_{6}- \\
& -4 M_{7}-4 M_{8}-4 M_{9}-4 M_{10}, \\
& 32 \rho_{3}=M_{1}+M_{2}-M_{3}-M_{4}-6 M_{5}+6 M_{6}+ \\
& +4 i M_{7}-4 i M_{8}-4 i M_{9}+4 i M_{10}, \\
& 32 \rho_{4}=M_{1}+M_{2}-M_{3}-M_{4}-6 M_{5}+6 M_{6}- \\
& -4 i M_{7}+4 i M_{8}+4 i M_{9}-4 i M_{10} \\
& 32 \rho_{5}=M_{1}+M_{2}-M_{3}-M_{4}+2 M_{5}-2 M_{6} \text {, } \\
& 32 \rho_{6}=M_{1}+M_{2}+M_{3}+M_{4}-2 M_{5}-2 M_{6} \text {, } \\
& 32 \rho_{7}=M_{1}-M_{2}-M_{3}+i M_{4}+\sqrt{2}(1+i) M_{7}+ \\
& +\sqrt{2}(1-i) M_{8}-\sqrt{2}(1-i) M_{9}-\sqrt{2}(1+i) M_{10} \text {, } \\
& 32 \rho_{8}=M_{1}-M_{2}+M_{3}-i M_{4}+\sqrt{2}(1-i) M_{7}+ \\
& +\sqrt{2}(1+i) M_{8}-\sqrt{2}(1+i) M_{9}-\sqrt{2}(1-i) M_{10} \text {, } \\
& 32 \rho_{9}=M_{1}-M_{2}-M_{3}+i M_{4}-\sqrt{2}(1-i) M_{7}- \\
& -\sqrt{2}(1+i) M_{8}+\sqrt{2}(1+i) M_{9}+\sqrt{2}(1-i) M_{10}, \\
& 32 \rho_{10}=M_{1}-M_{2}+M_{3}-i M_{4}-\sqrt{2}(1+i) M_{7}- \\
& -\sqrt{2}(1-i) M_{8}+\sqrt{2}(1-i) M_{9}+\sqrt{2}(1+i) M_{10} \text {. }
\end{aligned}
$$

The above-given solution defines a defect-free generalized structure with the chemical formula
VHEFC $_{6} \mathrm{D}_{6} \mathrm{~A}_{4} \mathrm{~B}_{4} \mathrm{~K}_{4} \mathrm{M}_{4}$. In order to obtain the amplitudes of modulation functions for the superionic $\mathrm{Cu}_{6} \mathrm{PS}_{5} \mathrm{Br}$ structure, one has to make the following substitutions: $M_{1}=M_{\mathrm{Br}}, \quad M_{3}=M_{\mathrm{P}}, \quad M_{4}=M_{\mathrm{S}(1)}, \quad M_{6}=M_{\mathrm{Cu}}, \quad M_{10}=M_{\mathrm{S}(2)}$, $M_{2}=M_{5}=M_{7}=M_{8}=M_{9}=0$. Then, one can obtain:

$$
\begin{aligned}
& \rho_{1}=1 / 32\left(M_{\mathrm{Br}}+M_{\mathrm{P}}+M_{\mathrm{S}(1)}+6 M_{\mathrm{Cu}}+4 M_{\mathrm{S}(2)}\right), \\
& \rho_{2}=1 / 32\left(M_{\mathrm{Br}}+M_{\mathrm{P}}+M_{\mathrm{S}(1)}+6 M_{\mathrm{Cu}}-4 M_{\mathrm{S}(2)}\right), \\
& \rho_{3}=1 / 32\left(M_{\mathrm{Br}}-M_{\mathrm{P}}-M_{\mathrm{S}(1)}+6 M_{\mathrm{Cu}}+4 i M_{\mathrm{S}(2)}\right), \\
& \rho_{4}=1 / 32\left(M_{\mathrm{Br}}-M_{\mathrm{P}}-M_{\mathrm{S}(1)}+6 M_{\mathrm{Cu}}-4 i M_{\mathrm{S}(2)}\right), \\
& \rho_{5}=1 / 32\left(M_{\mathrm{Br}}-M_{\mathrm{P}}-M_{\mathrm{S}(1)}-2 M_{\mathrm{Cu}}\right), \\
& \rho_{6}=1 / 32\left(M_{\mathrm{Br}}+M_{\mathrm{P}}+M_{\mathrm{S}(1)}-2 M_{\mathrm{Cu}}\right), \\
& \rho_{7}=1 / 32\left(M_{\mathrm{Br}}-i M_{\mathrm{P}}+i M_{\mathrm{S}(1)}-\sqrt{2}(1+i) M_{\mathrm{S}(2)}\right), \\
& \rho_{8}=1 / 32\left(M_{\mathrm{Br}}+i M_{\mathrm{P}}-i M_{\mathrm{S}(1)}-\sqrt{2}(1-i) M_{\mathrm{S}(2)}\right), \\
& \rho_{9}=1 / 32\left(M_{\mathrm{Br}}-i M_{\mathrm{P}}+i M_{\mathrm{S}(1)}+\sqrt{2}(1-i) M_{\mathrm{S}(2)}\right), \\
& \rho_{10}=1 / 32\left(M_{\mathrm{Br}}+i M_{\mathrm{P}}-i M_{\mathrm{S}(1)}+\sqrt{2}(1+i) M_{\mathrm{S}(2)}\right) .
\end{aligned}
$$

Within the framework of the superspace symmetry concept, the dispersion curves of the phonon spectra of complex crystals are defined as the solutions of the matrix equation under the condition that the determinant is equal to zero [12]:

$$
\left|D_{\alpha \beta}\left(\mathbf{k}+\mathbf{q}_{i}\right)-\omega^{2} \delta_{\alpha \beta} \delta_{i j}-\omega^{2} \rho_{(i-j)} \delta_{\alpha \beta}\right|=0 \text {, }
$$



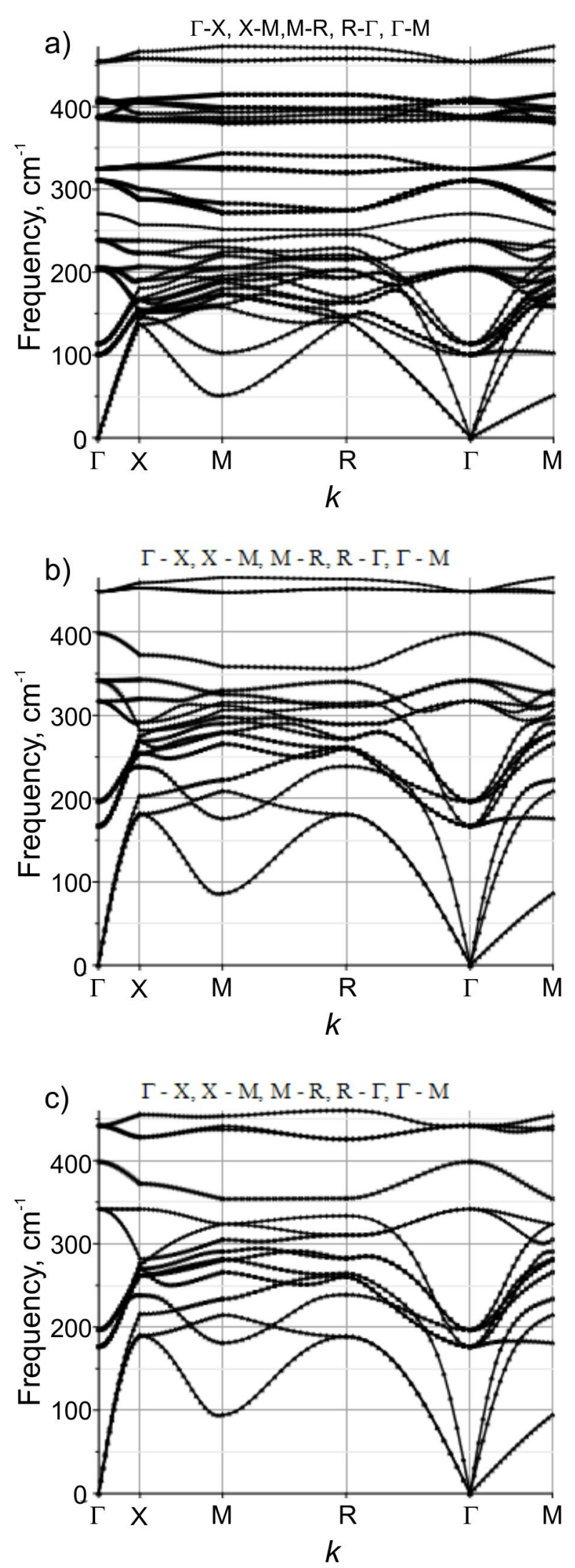

Fig. 2. Dispersion dependences for the crystal systems with the eliminated certain mass characteristics of subsystems and with the selected values of power constants for the $\mathrm{Cu}_{6} \mathrm{PS}_{5} \mathrm{Br}$ crystal: (a) $M_{\mathrm{Br}}=0$; (b) $M_{\mathrm{Br}}=0, M_{\mathrm{Cu}}=0$; (c) $M_{\mathrm{Br}}=0, M_{\mathrm{Cu}}=0, M_{\mathrm{S}(1)}=0$.
Table 3. Long-wave frequencies $\left(\mathrm{cm}^{-1}\right)$ in the cubic $\mathrm{Cu}_{6} \mathrm{PS}_{5} \mathrm{Br}$ crystal phase.

\begin{tabular}{|l|c|c|c|}
\hline Symmetry & Theory [9] & $\begin{array}{c}\text { Experiment } \\
{[9]}\end{array}$ & Our data \\
\hline $\mathrm{F}_{2}$ & $\begin{array}{c}72.3 \mathrm{i}(\mathrm{TO}) ; \\
59 \mathrm{i}(\mathrm{LO})\end{array}$ & & 99.0 \\
\hline $\mathrm{F}_{1}$ & $\begin{array}{c}51.7 \mathrm{i}(\mathrm{TO}) ; \\
20 \mathrm{i}(\mathrm{LO})\end{array}$ & & 100.4 \\
\hline $\mathrm{F}_{2}$ & 74.2 & 74 & 205.1 \\
\hline $\mathrm{F}_{1}$ & 80.8 & 78 & 209.1 \\
\hline $\mathrm{F}_{2}$ & 109.2 & & 269.7 \\
\hline $\mathrm{E}$ & 147.6 & 156 & 203.2 \\
\hline $\mathrm{A}$ & 206.0 & 234 & 270.7 \\
\hline $\mathrm{F}_{2}$ & 211.0 & 245 & 310.8 \\
\hline $\mathrm{F}_{1}$ & 317.5 & & 329.8 \\
\hline $\mathrm{F}_{2}$ & 320.0 & 316 & 388.6 \\
\hline $\mathrm{E}$ & 347.0 & & 386.0 \\
\hline $\mathrm{F}_{2}$ & 348.9 & & 406.5 \\
\hline $\mathrm{A}$ & 415.4 & 427 & 409.6 \\
\hline $\mathrm{F}_{2}$ & $\begin{array}{c}51.3 \mathrm{i}(\mathrm{TO}) ; \\
521 \mathrm{i}(\mathrm{LO})\end{array}$ & $547(\mathrm{TO}) ;$ & $458(\mathrm{LO})$ \\
\hline
\end{tabular}

where $\alpha, \beta$ are $x, y, z ; \mathbf{k}$ is the wave vector; $\mathbf{q}_{i}$ are the modulation vectors; $\rho_{i}\left(\mathbf{q}_{i}, \mathbf{b}^{*}\right)-$ amplitudes of the mass modulation function, which are defined for the modulation vectors $\mathbf{q}_{i},-\mathbf{q}_{j} ; D_{\alpha \beta}\left(\mathbf{k}+\mathbf{q}_{i}\right)-$ the dynamic matrixes of the monatomic BCC crystal, which are defined in the $\mathbf{k}+\mathbf{q}_{i}$ point of the Brillouin zone $(i=1,2, \ldots, 32)$ as:

$D_{\alpha \beta}\left(\mathbf{k}+\mathbf{q}_{i}\right)=\sum_{(n \neq 0)} a_{n} \frac{n_{\alpha} n_{\beta}}{n^{2}}\left(1-e^{i\left(\mathbf{k}+\mathbf{q}_{i}\right) \mathbf{n}}\right)$,

where $\alpha_{n}$ is the power constant between 0 and the $n$-th neighbor, $n_{\alpha}, n_{\beta}$ are the projections of the vector $\mathbf{n}$ on the $\alpha, \beta$ axes.

Calculations of the phonon spectra for the $\mathrm{Cu}_{6} \mathrm{PS}_{5} \mathrm{Br}$ crystal have been carried out in the Maple software environment. The calculated dispersion dependences of the phonon branches for the $\mathrm{Cu}_{6} \mathrm{PS}_{5} \mathrm{Br}$ crystal (along the lines $\Gamma-\mathrm{X}-\mathrm{M}-\mathrm{R}-\Gamma-\mathrm{M})$ are given in Fig. 1 . The employed software allows one to distinguish phonon dependences associated with certain compositionalstructural moieties (Fig. 2) by eliminating their mass characteristics. The results obtained for the $\Gamma$ point and their comparison with the literature data are presented in Table 3 .

\section{Conclusions}

Comparison of the dispersion curves calculated here for the $\mathrm{Cu}_{6} \mathrm{PS}_{5} \mathrm{Br}$ crystal with the earlier data of the Raman scattering and the first-principle calculations shows that the results are in good agreement with each other. Additionally, the correlations of the values of the lowfrequency optical branches $F_{2}, F_{1}$ with the values $\alpha_{2}=$ $2.4 \mathrm{~N} / \mathrm{m}$ for the system "P - S(2)" can be clearly observed. 


\section{References}

1. Studenyak I.P., Kus P. Structural Disorder in Crystalline and Amorphous Superionic Conductors. Uzhhorod: Hoverla, 2016.

2. Cao J., He R., Kyu T. Fire retardant, superionic solid state polymer electrolyte membranes for lithium ion batteries. Current Opinion in Chemical Engineering. 2017. 15. P. 68-75.

3. Senthilkumar S.T., Abirami M., Kim J., Go W., Hwang S.M., Kim Y. Sodium-ion hybrid electrolyte battery for sustainable energy storage applications. Journal of Power Sources. 2017. 341. P. 404-410.

4. Strauss F., Bartsch T., de Biasi L., Kim A-Y., Janek J., Hartmann P., Brezesinski T. Impact of cathode material particle size on the capacity of bulk-type all-solid-state batteries. ACS Energy Lett. 2018. 3. P. 992-996.

5. Kuhs W. F., Nitsche R., Scheunemann K. The argyrodites - a new family of the tetrahedrally close-packed structures. Mat. Res. Bull. 1979. 14, No 2. P. 241-248.

6. Nilges T., Pfitzner A. A structural differentiation of quaternary copper argyrodites: Structure - property relations of high temperature ion conductors. $Z$. Kristallogr. 2005. 220. P. 281-294.

7. Haznar A., Pietraszko A., Studenyak I.P. X-ray study of the superionic phase transition in $\mathrm{Cu}_{6} \mathrm{PS}_{5}$ Br. Solid State Ionics. 1999. 119. P. 31-36.

8. Sidey V., Shteyfan A. Revised bond valence parameters for the $\mathrm{P}^{+5} / \mathrm{S}^{-2}$ ion pair. J. Phys. Chem. Solids. 2017. 103. P. 73-75.

9. Studenyak I.P., Rushchanskii K.Z., Buchuk R.Yu., Stephanovich V.O. Phonon spectra of $\mathrm{Cu}_{6} \mathrm{PS}_{5} \mathrm{Br}$ superionic ferroelastic: experimental and theoretical studies. Condensed Matter Physics. 2007. 10. P. $11-16$.

10. Janssen T. Dynamics of aperiodic crystals. Ferroelectrics. 2000. 236. P. 157-168.

11. Fu L., Kane C.L., Mele E. J. Topological insulators in three dimensions. Phys. Rev. Lett. 2007. 98. P. 106803(4).

12. Nebola I.I., Ivanyas O.F., Kindrat V.Y. The genesis of the structure and vibrational spectra of crystals with the $(\mathrm{Sa} \times \mathrm{Sa} \times \mathrm{Sa})$ superlattice. Solid State Physics. 1993. 35. P. 1852-1866 (in Russian).

\section{Authors and CV}

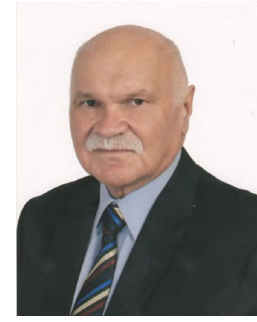

Ivan I. Nebola, born in 1947, defended his Doctoral Dissertation in Physics and Mathematics in 1994 and became full professor in 1997. Head of Department of Applied Physics at Uzhhorod National University, Ukraine. Authored over 140 publications. The area of scientific interests includes symmetry and calculation of dispersion dependencies of single particle spectra in condensed matter physics.

Uzhhorod National University

E-mail: ivan.nebola@uzhnu.edu.ua

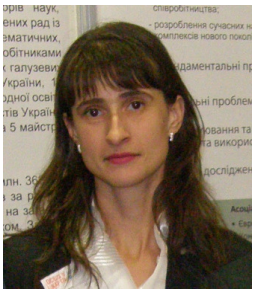

Aleksyna Ya. Shteyfan, born in 1980. Scientific co-worker at Uzhhorod National University, Ukraine. Authored over 40 publications. The area of her scientific interests includes the dispersion laws and theoretical-group analysis of phonon spectra of crystals with variable composition. Calculations of the phonon spectra of such crystals by using the superspace symmetry concept with modeling of the interatomic interaction.

Uzhhorod National University

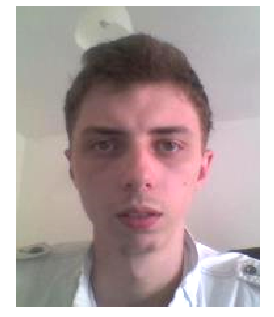

Anton F. Katanytsia, born in 1994. Student of Physics Faculty at Uzhhorod National University, Ukraine. Authored one publication. The area of his scientific interests includes structural parameters of complex crystals.

\section{Uzhhorod National University}

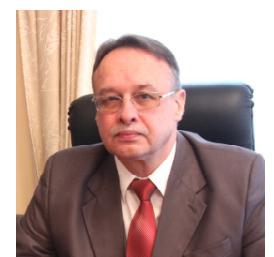

Ihor P. Studenyak, born in 1960, defended his Doctoral Dissertation in Physics and Mathematics in 2003 and became full professor in 2004 . Vicerector for Research at Uzhhorod National University, Ukraine. Authored over 200 publications, 115 patents, 15 textbooks. The area of his scientific interests includes physical properties of semiconductors, ferroics and superionic conductors.

Uzhhorod National University

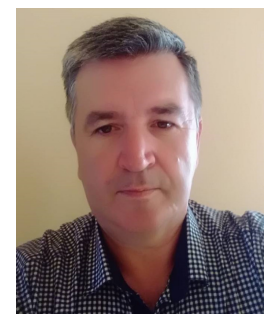

Ihor M. Shkyrta, born in 1965, Senior Lecturer, Mukacheve State University, Ukraine. Authored over 40 publications, one patent. The area of his scientific interests includes lattice dynamics and physical properties of semiconductors, ferroics and superionic conductors within the framework of superspace symmetry conception. Mukachevo State University 